\title{
Bitcoin and Future of Cryptocurrency
}

\author{
Afzalur Rahman* and Ayub Khan Dawood ${ }^{\star}$
}

\begin{abstract}
There are diverse variables that impact the future usage of bitcoin, from issues related to security to concerns pertaining to garnering acceptance from the market and customers. In this article, few predictive statements have been analysed regarding the future of bitcoin, such as (1) the growth of share of digital purchases, (2) customer acceptance for blockchain innovation in electronic settlements, payment and banking system, (3) the emergence of bitcoin and also various other cryptocurrencies as niche cash, and (4) the implications of bitcoin or some other cryptocurrency as a specific niche cash in nations with specifically weak currency, and (5) the possibilities of regulative dangers of bitcoin usage in these nations.
\end{abstract}

Keyword: Bitcoin and Cryptocurrency, Digital Payments, Payment Systems, Regulation

\section{Introduction}

Satoshi Nakamoto (2018) had observed that bitcoin was silently presented to the globe as an odd item of code in 2009 (Nakamoto, 2018). For even more than a year after its introduction, the bitcoin in circulation were traded for dimes, when a community of programmers made small adjustments and improvements to the open resource code at the system's level. It's worth scaled up to

\footnotetext{
* B S Abdur Rahman Crescent Institute of Science and Technology, Chennai, India; hodcommerce@crescent.education

† B S Abdur Rahman Crescent Institute of Science and Technology,

Chenai, India; dean.ssh@crescent.education
} 
about $\$ 1$ by February 2011, and subsequently, touched $\$ 30$ in four months, prior to the reduction of its worth from July 2011 to February 2012 to $\$ 8.16$. It touched the highest price in 2017 at approximately $\$ 19,871$ (Yahoo, 2018). However, the worth went down significantly in 2018 and the minimum price at the time of the preparation of the manuscript was recorded at $\$ 3184.4$ on January 27, 2019.

Bitcoin is approved around the globe as a mode of currency across a diverse range of services, operating both digitally and on the grounds. However, there are several questions with reference to the future of bitcoin or cryptocurrency. In this article, an attempt is being made to analyse a few observations regarding bitcoins. There are several perspectives regarding the future of bitcoin. While few applaud the emergence of bitcoin as a blockchain innovation, others find themselves settling for a more conservative approach.

The article, however, proposes that few observations could be made on the performance of bitcoins in the market, such as

1. The share of digital purchases could escalate;

2. Blockchain innovation could refine electronic repayments;

3. Bitcoin and various other cryptocurrencies could be the sole alternative for specific niche cash;

4. Bitcoin or other cryptocurrencies could operate than a particular niche loan in nations with weak money,

5. In addition to (4), these nations would certainly appear to posture the biggest governing threat to bitcoin.

\section{Bitcoin and the Unavoidable Money Problem}

The largest challenge to the extensive fostering of bitcoin is the unavoidable cash trouble. The choice to use bitcoin, in fact, threatens the government as an organisation. There are various types of economic, regulatory, legal, operational, customer protection and security issues that challenge the use of cryptocurrency. The first press release on crypto currency by Reserve Bank of India warned the user of cryptocurrency and virtual money because of its volatility, legal status and a chance of 
fraud in 2013. One of the major concerns with regards to cryptocurrency is its regulation to minimise involved risks. RBI in its second press release on February 1, 2017, cautioned the user, trader and holder of the cryptocurrency about the related risk associated with it. RBI also clarified that it has not given any licence and authority to anybody in India and outside India to to engage in business associations through cryptocurrency including Bitcoin (India, 2013). After three press releases, the last one being reelased on December 5, 2017, RBI took a firm decision and ordered all the other associated bodies to withdraw the service of facilitating the use of cryptocurrency in any form. The deadline was July 5, 2018. However even after this ban, the peer to peer option was still open continues to operate even now (Times, 2018). Apart from all these regulations in India and China in 2018, \$15.4 billion new cryptocurrency value was created in 2018 (Market and Prices, 2019).

\section{Competition from Alt-Coins}

Bitcoin is not only facing challenges with fiat money of any country or government agencies but also from the other cryptocurrencies that came in the market after its success, and are generally referred to as Alt Coins. The innovations in blockchain technology and its uses in altcoin make it a more preferred choice in the market. There are more than 2118 cryptocurrencies available for trading, with a mixed market capitalization of approximately \$ trillion as of 18 December 2017. Bitcoin controls the market in various ways, especially with a market capitalization of $\$ 587$ billion (Xinfinit Bita Terminal, 2019). The Center for Information and Industry Development (CCID) under Chinese's Ministry of Industry and Information Technology, published the first cryptocurrency ranking on the $24^{\text {th }}$ of January, 2019 (CCID, 2019). According to this ranking, Bitcoin takes the $15^{\text {th }}$ position in cryptocurrency ranking. In contrast, however, Bitcoin has the largest market share and due to its chronological advantage as the first cryptocurrency, enjoys the status of being a preferred mode of operation (coinmarketcap, 2019). 


\section{The Future of Digital Payments}

The technical breakthrough of bitcoin is its capability to procure purchases over a dispersed network, without the main node working as a financial institution. The clearing purchases making use of the blockchain appear to be less expensive than the standard techniques utilised otherwise. If the blockchain innovation decreases purchase expenses, it could be embraced to clear electronic repayments. The inclusion of bitcoins or its acceptance thereof could be understood in the following ways:

\section{i. The increasing trend of electronic payment system}

The rise in the online payment and ease in the payment using Bitcoin, particularly in case of inter-country transaction may attract the public to use bitcoin. The increase in the use of smartphone and public awareness regarding payment through virtual currency and its widespread acceptability could facilitate its popularity and vice versa.

\section{ii. The popularity of blockchain technology in the payment and clearing system}

Bitcoin substantiated the strength of blockchain technology. Witnessing the strength of the blockchain technology, the governments of different countries wanted to introduce this technology in the banking systems as a less expensive alternative (In the Black, 2018).

Iran has announced to start a government-backed cryptocurrency usage model in the month of January 2019. The government has planned to bein the use of this new cryptocurrency in phases. In the first phase, the cryptocurrency backed by the national fiat money i.e. Iranian rial will be issued to facilitate payment between an Iranian bank and other financial institutions that are active in cryptocurrency transaction. The government may introduce cryptorial as a payment option. Apart from this, Italy is also working to adopt a cryptocurrency regulation. India is also in the finalisation stage of preparing the regulations on cryptocurrency (Bitcoin.com, 2019). 


\section{Conclusion}

Bitcoin represents an imaginative and technically advanced alternative for an uncertain, globalised future. This could be a viable alternative for processing payments across geographical boundaries. Bitcoins, if regulated effectively, could help the future generations to meet the challenges comprising of issues pertaining to financial transcations in various forms.

\section{Referencs}

Bitcoin.com. (2019, January 28). The Daily. Retrieved from https://news.bitcoin.com: https://news.bitcoin.com/the-daily-iransaid-to-announce-crypto-rial-this-week-italy-closer-to-cryptoregulation/

CCID. (2019, 124$)$. CCID released the global public chain technology evaluation index No. 9: EOS, Ethereum still top two bitcoins rose by 3 to 15. Retrieved from http://www.ccidnet.com: http://www.ccidnet.com/ 2019/ 0124/ 10452682.shtml

coinmarketcap. (2019, January 27). Retrieved from https://coinmarketcap.com: https:// coinmarketcap.com/ currencies/ bitcoin-sv/

How governments are using blockchain technology. (2018, 8 22). Retrieved from https://www.intheblack.com: https://www.intheblack.com/ articles/2018/08/22/how-governments-using-blockchain-technology

India, R. B. (2013, December 24). PRESS RELEASES. Retrieved from https://rbi.org.in:

https://rbi.org.in/scripts/BS_PressReleaseDisplay.aspx?prid $=42462$

Levy, D., \& Andrew T, Y. (2014). The Real Thing: Nominal Price Rigidity of the Nickel Coke, 1886-1959. Journal of Money, Credit and Banking , 765-799.

Luther, W. (2014). Will Bitcoin Survive? Kenyon College Allumni Bulletin .

Market and Prices. (2019, January 27). Retrieved from https://news.bitcoin.com: https://news.bitcoin.com/15-4-billion-ofnew-cryptocurrency-value-was-created-during-2018/

Nakamoto, S. (2018). Bitcoin: A Peer-to-Peer Electronic Cash System. www.bitcoin.org .

Rizoo, P. (2015, July 14). Deloitte Trials Blockchain Tech for Client Auditing. Coin Desk.

Times, T. E. (2018, July 4). Are you a Bitcoin investor? Watch out for RBI's July 5 deadline . Retrieved from https:// economictimes. indiatimes.com: 
https://economictimes.indiatimes.com/news/economy/policy/bitco in-investors-watch-out-for-rbis-july-5-deadline/ articleshow / 64840136.cms

White, L. (2013). I Am Nassim Taleb, author of Antifangile, AMA. Reddit . Xinfinit Bita Terminal. (2019, January 27). Retrieved from https://terminal.xinfinit.com: https://terminal.xinfinit.com/ rest/ web/portal/Ws12_LPPu4t2pUG-LeggYSFy8k3P2Kt0/ page/ i5v NwwbRfVfTXmTku1NDFCFy8k3P2Kt0/s

Yahoo. (2018, October). Bitcoin USD (BTC-USD). Retrieved from https://finance.yahoo.com: https://finance.yahoo.com/quote/BTCUSD? $\mathrm{p}=$ BTC-USD 